\title{
Response to Letter by Finsterer and Zarrouk
}

\author{
Teck Wah Ting ${ }^{1,2} \cdot$ Saumya Shekhar Jamuar ${ }^{1,2}$
}

Received: 31 July 2015/Accepted: 4 August 2015/Published online: 14 August 2015

(C) Springer Science+Business Media New York 2015

We appreciate the interest shown by Finsterer et al. in our article [1]. We agree with Finsterer et al. that not all cases of left ventricular non-compaction (LVNC) are due to genetic etiologies. The possible causes can include acquired or environmental factors as stated in our discussion. The aim of our article is to define a strategy to evaluate the etiology of LVNC in paediatric patients when a genetic cause is suspected. As highlighted by Finsterer et al., we have included neuromuscular diseases (in Table 2) and mitochondrial disorders (in Table 3) as diseases associated with LVNC in our article.

Any conclusion on the pathogenesis on the mechanism remains speculative at best currently [2,3]. The genes listed in the Tables 3 and 4 have been reported to be associated with LVNC. We certainly do not mean to imply that association is equivalent to direct causal relationship, and the information in the tables is by no means exhaustive. They serve as a brief reference for the reader.

In summary, the aim of our article is to the approach to diagnose the underlying genetic causes in a pediatric patient with LVNC. We hope that it will be a useful resource for a busy clinician who is assessing a paediatric patient with LVNC.

\section{Compliance with Ethical Standards}

Conflict of interest The authors declare no conflict of interest.

\section{References}

1. Ting TW, Jamuar SS, Brett MS, Tan ES, Cham BW, Lim JY, Law HY, Tan EC, Choo JT, Lai AH (2015) Left ventricular noncompaction: is it genetic? Pediatr Cardiol. doi:10.1007/s00246015-1222-5

2. Finsterer J, Stöllberger C, Schubert B (2008) Acquired left ventricular noncompaction as a cardiac manifestation of neuromuscular disorders. Scand Cardiovasc J 42:25-30

3. Finsterer J, Stöllberger C (2013) Mitochondrial DNA sequence and copy number variants cannot be the only culprit in the pathogenesis of noncompaction. Mol Genet Metab 109(3):317
This is the response to the letter entitled, "Consider a Non-genetic Pathogenesis of Noncompaction”, doi:10.1007/s00246-015-1253-y.

Saumya Shekhar Jamuar

saumya.s.jamuar@kkh.com.sg

1 Genetics Service, Department of Paediatrics, KK Women's and Children's Hospital, 100 Bukit Timah Road,

Singapore 229899, Singapore

2 Singhealth Duke-NUS Paediatrics Academic Clinical Programme, Singapore, Singapore 